\title{
Descrição de uma espécie nova de Pimelodus (Siluriformes, Pimelodidae) da bacia do alto rio Paraguai
}

\author{
Hugo S. de Souza-Filho \& Oscar A. Shibatta
}

Programa de Pós-Graduação em Ciências Biológicas, Departamento de Biologia Animal e Vegetal, Centro de Ciências Biológicas, Universidade Estadual de Londrina. Rodovia Celso Garcia Cid, 86051-990 Londrina, PR, Brasil. (shibatta@uel.br)

\begin{abstract}
Description of a new species of Pimelodus (Siluriformes, Pimelodidae) from upper rio Paraguai basin. A new species, formerly identified as $P$. maculatus La Cepède, 1803 , is described. It differs from its congeners, except $P$. maculatus and $P$. mysteriosus Azpelicueta, 1998 by the color pattern with dark brown blotches in the flanks. The new species is morphometricaly similar to $P$. argenteus Perugia, 1891 and $P$. mysteriosus, differing, respectively, by the blotched color pattern and by the smaller maxillary barbel. The described new species differs from $P$. maculatus for presenting the supraoccipital process more robust, with base as broad as long (versus longer than broad); anterior nostrils 25\% of distance between the margin of snout to posterior nostrils (versus $33 \%$ of this distance); small saws in the pectoral spine more developed and present in more than half of the anterior margin of spine (versus small saws present in less than half of that margin); very thin skin covering the head, allowing the grooves in the bones surfaces conspicuous; 22 27 (mode=24) gill rakers in the first branchial arch [versus 19-24 (mode=21)]. This new species was also discriminated from P. maculatus in the size free canonical variates analysis by presenting larger values of interorbital distance, mouth width and maxillar barbel length and smaller base length of adipose-fin.
\end{abstract}

KEYWORDS. Catfishes, Neotropical, Pantanal, systematics.

RESUMO. Uma espécie nova, correntemente identificada como P. maculatus La Cepède, 1803, é descrita. Ela difere das demais espécies do gênero, exceto de P. maculatus e P. mysteriosus Azpelicueta, 1998, pelo padrão de colorido com máculas escuras sobre os flancos. A nova espécie é morfometricamente similar a $P$. argenteus Perugia, 1891 e $P$. mysteriosus, mas difere destas, respectivamente, pelo padrão de colorido maculado e pelo menor comprimento do barbilhão maxilar. Difere de $P$. maculatus por apresentar o processo supra-occipital mais robusto, com a base quase tão larga quanto o comprimento (versus mais comprido do que largo); narinas anteriores a $25 \%$ da margem anterior do focinho, na distância entre o início do focinho até as narinas posteriores (versus 33\% dessa distância); serrilhas do acúleo peitoral mais desenvolvidas e presentes em mais da metade da margem anterior do acúleo (versus serrilhas leves e presentes em menos da metade desta margem); pele que recobre a cabeça muito fina, tornando conspícuas as estrias da superfície dos ossos; 22-27 (moda=24) rastros no primeiro arco branquial [versus 19-24 (moda=21)]. Também foi discriminado de $P$. maculatus na análise morfométrica multivariada das variáveis canônicas livres do tamanho, por apresentar maiores valores da distância interorbital, largura da boca e comprimento do barbilhão maxilar e menor comprimento da base da nadadeira adiposa.

PALAVRAS-CHAVE. Bagres, Neotropical, Pantanal, sistemática.

A bacia do rio Paraguai é conhecida pela riqueza de suas espécies de peixes, mas poucos estudos de revisão taxonômica com essas espécies foram publicados. Com o recente aporte de material da região alta desta bacia no Museu de Zoologia da Universidade Estadual de Londrina (MZUEL), foi possível estudar as espécies de Pimelodus La Cepède, 1803 do Pantanal com profundidade. Na região do Pantanal são estimadas 325 espécies de peixes (WILlink et al., 2000), dentre as quais quatro foram apontadas por BRITSKI et al. (1999) para o gênero Pimelodus: P. argenteus Perugia, 1891; P. cf. fur (Reinhardt, 1874); P. maculatus La Cepède, 1803 e $P$. ornatus Kner, 1857. Além dessas espécies, P. mysteriosus Azpelicueta, 1998 pode ser incluída na lista, pois a sua área de distribuição também abrange a região de Cáceres, estado do Mato Grosso (AzPelicueta, 1998), e $P$. cf. $f u r$ deve ser identificada como $P$. absconditus Azpelicueta 1995. Dessas espécies destaca-se a que é identificada como Pimelodus maculatus, pois nossos estudos apontam que ela representa uma nova espécie da bacia do alto rio Paraguai.

Pimelodus é o gênero mais diversificado da família Pimelodidae, contendo 24 espécies válidas (LUNDBERG \& LitTMAN, 2003). Identificar seguramente o gênero ainda é um problema, pois nenhum caráter apomórfico foi reconhecido. LUNDBERG et al. (1991) mencionaram uma possível sinapomorfia relativa aos forames do nervo trigeminofacial, presente em Pimelodus maculatus, espécie-tipo do gênero, além de outras espécies de Pimelodus, mas que foi posteriormente observada em outros representantes de Pimelodidae (LUNDBERG \& PARISI, 2002). O que se tem utilizado, portanto, são caracteres morfológicos tais como presença ou ausência de dentes no vômer em pequenos retalhos, fontanela não se estendendo para trás além dos olhos, processo póscleitral largo, topo da cabeça granuloso, espinhos das nadadeiras peitorais e dorsal fortes (EIGENMANN \& EIGENMANN, 1890), processo pós-occipital alcançando a placa pré-dorsal, olhos com margem orbital livre, barbilhões teretes, espinho peitoral forte e denteado em ambas as margens, nadadeira anal com 10 a 13 raios, nadadeira caudal furcada com lobos pontiagudos (RINGUELET et al., 1967), lábios normais sem margem livre em sua parte superior, cabeça mais ou menos deprimida, boca grande (BRITSKI, 1972), tamanho moderado a grande, barbilhões longos, barbilhões maxilares usualmente alcançando a base da nadadeira caudal ou próximo, um pequeno poro acima da parte posterior da base da 
nadadeira peitoral, ou ausente (MeEs, 1974), maxila superior um pouco mais longa que a mandíbula e a base da nadadeira adiposa mais longa que a anal (BRITSKI et al., 1999).

Além da espécie nova, que é descrita neste trabalho, apresentamos uma chave de identificação de todas as espécies de Pimelodus do Pantanal e fotos que facilitam a sua identificação.

\section{MATERIAL E MÉTODOS}

As medidas foram tomadas ponto a ponto em linha reta, diretamente sobre o lado esquerdo do peixe, com auxílio de um paquímetro digital com precisão de $0,01 \mathrm{~mm}$. Para a escolha das medidas e contagens seguiu-se AzPELICUETA (1995) com modificações. O comprimento da cabeça não incluiu a membrana opercular e foram adicionadas as seguintes medidas: altura do pedúnculo caudal (obtida na região mais estreita), largura da cintura peitoral (na região mais larga), comprimento do barbilhão maxilar (da base até a extremidade) e distância entre a base das nadadeiras dorsal e adiposa (espaço entre as nadadeiras dorsal e adiposa). Medidas da cabeça foram expressas como porcentagens do comprimento da cabeça (CC) e as medidas do corpo como porcentagens do comprimento padrão $(\mathrm{CP})$. Os valores mínimos e máximos das porcentagens dos dados morfométricos foram apresentados, com a média entre parênteses. Assim como em Azpelicueta (1995), a trava do acúleo dorsal foi incluída na contagem como sendo um raio duro indiviso.

Para a discriminação das espécies foi utilizada a análise das variáveis canônicas livres do tamanho (AVCLT), através do pacote estatístico SAS, conforme o protocolo de ReIs et al. (1990).

As preparações osteológicas foram realizadas manualmente sob microscópio estereoscópico.

As amostras foram provenientes de diferentes localidades da bacia do alto rio Paraguai (Fig. 1). As abreviações utilizadas neste estudo são: CESP, Companhia Energética de São Paulo; ECPUEL, Equipe de Coleta de Peixes da Universidade Estadual de Londrina; LAPAD, Laboratório de Biologia e Cultivo de Peixes de Água Doce da Universidade Federal de Santa Catarina; LIS, Laboratório de Ictiologia e Sistemática do Departamento de Ecologia e Biologia Evolutiva da Universidade Federal de São Carlos; MZUL, Museu de Zoologia da Universidade Estadual de Londrina; MZUSP, Museu de Zoologia da Universidade de São Paulo; NUP, Núcleo de Pesquisas em Limnologia, Ictiologia e Aqüicultura da Universidade Estadual de Maringá (NUPÉLIA).

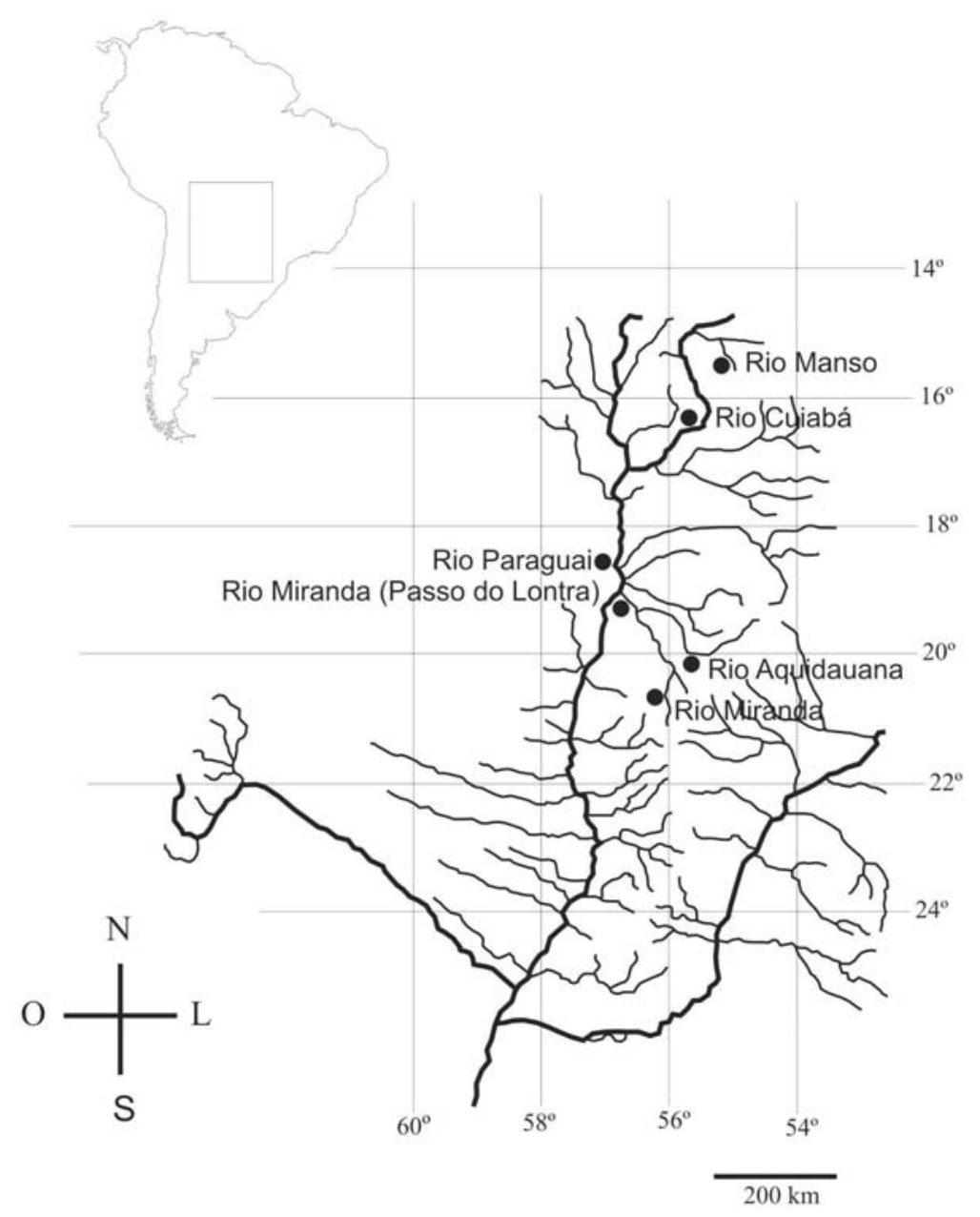

Fig. 1. Mapa com os locais de coleta de Pimelodus pantaneiro sp. nov. na bacia do alto rio Paraguai. 
Material comparativo examinado. Pimelodus absconditus Azpelicueta, 1995. BRASIL, Mato Grosso: Chapada do Guimarães (reservatório Manso), 12, 2000-2003, NUPÉLIA col. (NUP 904); 7, 2000-2002, NUPÉLIA col. (NUP 2228); Mato Grosso do Sul: Bonito (rio Miranda), 5, X.1999, O. A. Shibatta col. (MZUL 3402). Pimelodus argenteus Perugia, 1891. BRASIL, Mato Grosso: Chapada dos Guimarães (reservatório Manso), 7 , 2000-2003, NUPÉLIA col. (NUP 991); Mato Grosso do Sul: Corumbá (rio Paraguai, Porto da Manga), 8, I.2002, O. A. Shibatta \& L. Souza col. (MZUL 3403); 9, I.2002, O. A. Shibatta \& L. Souza col. (MZUL 3498); Bonito (rio Miranda), 1, XII.1999, O. A. Shibatta col. (MZUL 3401); 10, XII.1999, O. A. Shibatta col. (MZUL 3404). Pimelodus atrobrunneus Vidal \& Lucena, 1999. BRASIL, Rio Grande do Sul: Machadinho (rio Uruguai), V.2002, LAPAD col. (MZUL 3600). Pimelodus fur (Lütken, 1874). BRASIL, Minas Gerais: (rio São Francisco e afluentes, área do projeto UHE/Formoso), 4, XI.1987 a VIII.1988, Y. Sato col. (MZUSP 39748). Pimelodus maculatus La Cepède, 1803. BRASIL, São Paulo: Rosana (rio Paranapanema, lagoa Paredão) 1, I.1991, S. Britto col. (MZUL 2794); Palmital (rio Paranapanema, jusante de Salto Grande), 1, 1992, CESP col. (MZUL 2628); Águas de Santa Bárbara (rio Novo, afluente do rio Paranapanema), 1, IV.1992, CESP col. (MZUL 2202); Ourinhos (rio Turvo, afluente do rio Paranapanema), 1, 1991, CESP col. (MZUL 2245); (rio Paranapanema, ponte da ferrovia), 1, III.1993, CESP col. (MZUL 2630); 1, 1992, CESP col. (MZUL 2788); Angatuba (rio Paranapanema), 11, II.2001, E. Carvalho col. (MZUL 1865) (rio Paranapanema, lagoa do Mian), 2, VIII.1999, M. Orsi col. (MZUL 2356); Paraná: Sertaneja (rio Congonhas, afluente do rio Tibagi), 2, XI.1996, ECPUEL col. (MZUL 859); Ipiranga (rio Tibagi), 1, IV.1990, ECPUEL col. (MZUL 879); Londrina (ribeirão Três Bocas, afluente do rio Tibagi), 1, V.1993, L. G. Caetano col. (MZUL 1282) 1, XII.1992, L. G. Caetano col. (UEL 1283); 2, III.1990, L. G. Caetano col. (MZUL 1308); 1 , IX.1987, L. G. Caetano col. (MZUL 1309); 7, sem data, L. G. Caetano col. (MZUL 1343); 1, V.1992, ECPUEL col. (MZUL 1391); Sapopema (rio Tibagi), 1, IX.1998, ECPUEL col. (MZUL
1567); Pedra Branca (rio Paranapanema), 1, X.1992, CESP col. (MZUL 2210); 1, XII.1992, ECPUEL col. (MZUL 2797); Ribeirão Claro (rio Paranapanema), 1, I.1994 (MZUEL 2652); Itambaracá (rio Paranapanema), 4, III.2003, ECPUEL col. (MZUL 3315) Santa Catarina: Itá (rio Uruguai, reservatório de Itá), 1, 1995, LAPAD-UFSC col. (MZUL 4306); ARGENTINA, Buenos Aires: Beriso (Río de La Plata, Balneario municipal), 2, I.1990, M. M. Azpelicueta col. (LIS 1142); Ensenacha (Arroyo La Guardia, a $100 \mathrm{~m}$ da boca do rio La Plata, Punta Hora), 1, XI.1991, M. M. Azpelicueta \& A. Martinez col. (LIS 1143); Punta Lara (Boca Cerrada), 3, II.1989, L. Martinez \& Lucas col. (LIS 1144). Pimelodus mysteriosus Azpelicueta, 1998. BRASIL, Mato Grosso: Chapada dos Guimarães (reservatório Manso), 2, VI.1999, K. Z. S. Silimon col. (NUP 1973); Chapada dos Guimarães (reservatório Manso), 5, 2000-2001, NUPÉLIA col. (NUP 2229); Mato Grosso do Sul: Bonito (rio Miranda), 1, XII.1999, O. A. Shibatta col. (MZUL 3400); 1, XII.1999, O. A. Shibatta col. (MZUL 3607). ARGENTINA, Missiones: Posadas (rio Paraná), 1, IV.1996, H. Roncati col. (MZUL 3598). Pimelodus ornatus Kner, 1857. BRASIL, Mato Grosso: Chapada dos Guimarães (reservatório Manso), 9, III-IV.2000, NUPÉLIA col. (NUP 3606); (reservatório Manso, afluente do rio Paraguai), 7, 14.iii26.iv.2000, NUPÉLIA col. (NUP 1045); Mato Grosso do Sul: Aquidauana (rio Aquidauana), 1, XI.2000, M. Caetano Filho col. (MZUL 3606); São Paulo: Rosana (rio Paraná, tributário de Rosana), 1, 1992, CESP col. (MZUL 2816); Paraná: Porto Primavera (rio Paraná), 2, V.1993, CESP col. (MZUL 3405); Jataizinho (rio Tibagi), 1, X.2004, J. Piola col. (MZUL 3605).

\section{RESULTADOS}

Pimelodus pantaneiro, sp. nov. (Figs. 2A e B)

Pimelodus maculatus, Britski, Silimon \& Lopes, 1999:99, 101 (diagnose, chave de identificação e ilustração).

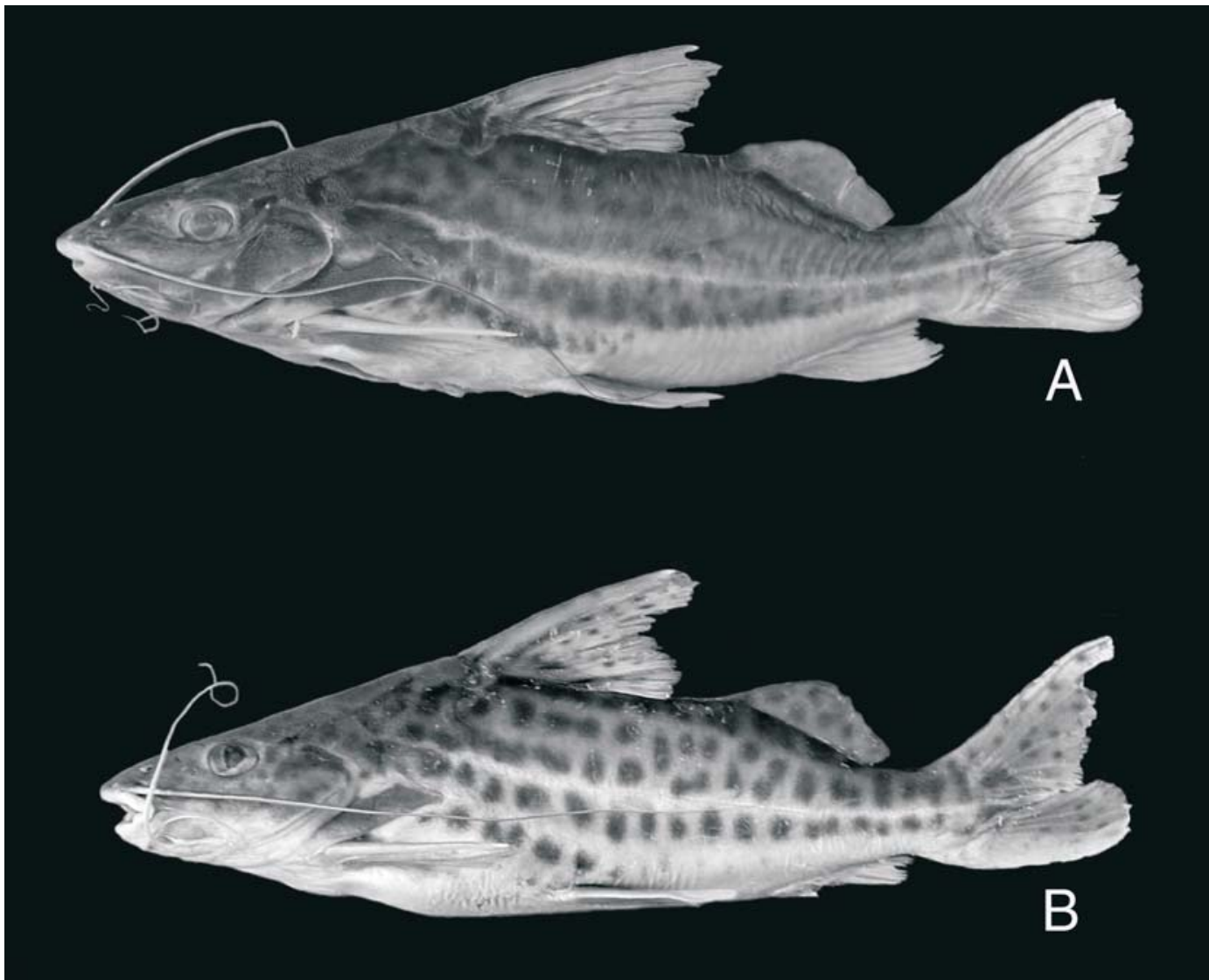

Fig. 2. Pimelodus pantaneiro sp. nov., A, holótipo, MZUSP 87808, 228,4 mm CP, rio Miranda, Bonito, Mato Grosso do Sul; B, parátipo, MZUL 3567, 181,7 mm CP, rio Pixaim e corixos próximos, drenagem do rio Cuiabá, Poconé, Mato Grosso. 
Material tipo: Holótipo, BRASIL, Mato Grosso do Sul: Bonito (rio Miranda), X.1999, O. A. Shibatta, M. Caetano Filho, \& J. H. Leonhardt col. (MZUSP 87808). Parátipos, Mato Grosso: Poconé (rio Pixaim e corixos próximos), 1, VII.1999, ECPUEL col. (UEL 3567); 2, VII.1999, ECPUEL col. (MZUL 3665); Chapada dos Guimarães (reservatório Manso), 5, 2000, NUPÉLIA col. (NUP 2225); Mato Grosso do Sul: Corumbá (rio Miranda, Passo do Lontra), 3, V.1991, M. Caetano Filho col. (MZUL 3398); (rio Paraguai, Porto da Manga), 10, I.2002, O. A. Shibatta \& L. Souza col. (MZUL 3399); 1, I.2002, O. A. Shibatta \& L. Souza col. (MZUL 3554); Bonito, 3, mesmas informações de coleta do holótipo (MZSP 87809); 2, mesmas informações de coleta do holótipo (UEL 3601); 3, X.1999, O. A. Shibatta col. (MZUL 1912); 4, X.1999, O. A. Shibatta, M. Caetano Filho \& J. H. Leonhardt col. (MZUL 3599).

Diagnose. Difere das demais espécies do gênero, com exceção de $P$. maculatus e $P$. mysteriosus, por apresentar máculas grandes, às vezes maiores que o diâmetro do olho, dispostas em três a cinco fileiras ao longo do corpo. Os seguintes caracteres distinguem $P$. pantaneiro de $P$. maculatus: processo supra-occipital mais robusto, com a base quase tão larga quanto o comprimento (versus mais comprido do que largo em $P$. maculatus); narinas anteriores mais próximas à borda da boca ( $25 \%$ da distância entre a borda da boca e as narinas posteriores, versus 33\%); serrilhas do acúleo peitoral mais desenvolvidas e ocupando mais da metade da borda anterior do acúleo (ocupando menos da metade em $P$. maculatus); tegumento da cabeça muito fino, tornando conspícua a superfície estriada dos ossos (o que não ocorre em $P$. maculatus); maior número de rastros no primeiro arco branquial 22-27 [moda $=24$, versus $19-24$ (moda=21)] e nas proporções corporais por apresentar, em média, uma maior distância interorbital, largura da boca e comprimento do barbilhão maxilar e menor comprimento da base da nadadeira adiposa (Tab. I). Difere de P. mysteriosus, outra espécie com características morfológicas similares, pelos menores comprimentos do barbilhão maxilar, que pode ultrapassar a nadadeira adiposa (mas, geralmente, não a base da nadadeira

Tabela I. Valores mínimos e máximos das proporções corporais (médias entre parênteses) das espécies do gênero Pimelodus da bacia do alto rio Paraguai e da espécie Pimelodus maculatus da bacia do rio Paraná e Uruguai. Medidas da cabeça como proporções do comprimento da cabeça e medidas do corpo como proporções do comprimento padrão, inclusive o comprimento da cabeça.

\begin{tabular}{|c|c|c|c|c|c|c|}
\hline Variáveis & $\begin{array}{l}\text { Pimelodus } \\
\text { absconditus } \\
\quad(\mathrm{N}=27)\end{array}$ & $\begin{array}{c}\text { Pimelodus } \\
\text { argenteus } \\
(\mathrm{N}=35)\end{array}$ & $\begin{array}{c}\text { Pimelodus } \\
\text { maculatus } \\
(\mathrm{N}=43)\end{array}$ & $\begin{array}{l}\text { Pimelodus } \\
\text { mysteriosus } \\
\quad(\mathrm{N}=23)\end{array}$ & $\begin{array}{c}\text { Pimelodus } \\
\text { ornatus } \\
(\mathrm{N}=10)\end{array}$ & $\begin{array}{l}\text { Pimelodus } \\
\text { pantaneiro } \\
(\mathrm{N}=35)\end{array}$ \\
\hline $\begin{array}{l}\text { 1. Comprimento padrão } \\
(\mathrm{mm})\end{array}$ & $35,2-172,5$ & $107,1-212$ & $86,6-229,4$ & $57,7-205,4$ & $76,5-265$ & $112,6-256,4$ \\
\hline 2. Comprimento da cabeça & $25,9-29,2(27,1)$ & $26-31,2(28,4)$ & $27-31,9(29,2)$ & $26,7-31,9(29,2)$ & $31,2-32,2(31,8)$ & $26,3-30,5(28,3)$ \\
\hline 3. Diâmetro do olho & $23,7-37,3(29,4)$ & $24,1-29,7(26,4)$ & $20,7-28,9(25,3)$ & $22,5-33,2(27,7)$ & $16,2-28,8(20,5)$ & $20,1-30,1 \quad(23,5)$ \\
\hline 4. Distância interorbital & $20,4-26,6(23,5)$ & $28,7-37,6(33,3)$ & $22-29,4(25,6)$ & $27,9-39,2(31,7)$ & $23,7-32,9(29,3)$ & $30,9-41,7(36,4)$ \\
\hline $\begin{array}{l}\text { 5. Comprimento do } \\
\text { focinho }\end{array}$ & $36,8-51(46,6)$ & $44,7-50,4(47,8)$ & $43,8-51,5(47)$ & $42,1-49,1(46)$ & $46,2-48,3(47,3)$ & $44,2-54,5(48,4)$ \\
\hline 6. Largura da boca & $28-37,2(32,2)$ & $32,1-40,7(36,4)$ & $28,7-40,6(34,6)$ & $32,6-40,6(36)$ & $41,8-49,7(44,6)$ & $36,5-49,5(40,1)$ \\
\hline 7. Distância pré-dorsal & $37,9-41,4(39,5)$ & $40,2-46,5(42,5)$ & $39,4-45,4(42,9)$ & $41-47,3(43,5)$ & $40,5-44(42,8)$ & $40,1-44,8(42,4)$ \\
\hline $\begin{array}{l}\text { 8. Comprimento da base } \\
\text { da dorsal }\end{array}$ & $15,6-18,8(16,8)$ & $15,4-18,3(17)$ & $13,5-16,8(15,3)$ & $14,9-18(16,5)$ & $15,7-17,6(16,7)$ & $15-17,1(16,0)$ \\
\hline 9. Distância pré-ventral & $49,8-54,4(51,8)$ & $50,8-56,1(53,3)$ & $50,3-56,5(53,1)$ & $49,7-55,5(53,4)$ & $44,2-55,3(52,5)$ & $50,3-56,6(53,6)$ \\
\hline 10. Distância ventral anal & $18,4-25,2(21,7)$ & $18,5-23,1(20,9)$ & $19,1-24,6(21,7)$ & $18,9-23,8(21,5)$ & $18,6-22,4(20,2)$ & $19,3-23,4(20,8)$ \\
\hline 11. Altura da cabeça & $50,8-65,9(57,8)$ & $52,7-66,3(59,4)$ & $43-67,7(54,9)$ & $53,2-67,3(58)$ & $42,3-50,9(46,6)$ &, $2(61,5)$ \\
\hline 12. Altura do corpo & $25,1-32,7(27,6)$ & $26,5-33,1(29,9)$ & $24,6-31,5(27,4)$ & $27-32,6(29,2)$ & $24,8-28,6(26,4)$ & $26,9-35(30,3)$ \\
\hline $\begin{array}{l}\text { 13. Altura do pedúnculo } \\
\text { caudal }\end{array}$ & $8,4-10,2(9,1)$ & $7,9-10,2(9,2)$ & $8,4-10,8(9,5)$ & $8,4-10(9,13)$ & $7,5-8,2(7,9)$ & $8,1-10,2(9,3)$ \\
\hline $\begin{array}{l}\text { 14. Largura da cintura } \\
\text { escapular }\end{array}$ & $18,4-20,8(19,4)$ & $19,9-23,2(21,5)$ & $18,4-21,5(19,9)$ & $20,6-23,2(22,0)$ & $20,7-24,6(22,3)$ & $20,3-23,8(22,2)$ \\
\hline $\begin{array}{l}\text { 15. Comprimento do } \\
\text { barbilhão maxilar }\end{array}$ & $75,1-125,6(97,4)$ & $75,1-137,2(100,9)$ & $42,7-87,8(74,1)$ & $89,2-152,1(112,3)$ & $52,4-98,6(74,3)$ & $61,9-105,4(89,3)$ \\
\hline $\begin{array}{l}\text { 16. Comprimento do } \\
\text { acúleo peitoral }\end{array}$ & $10,3-21,3(18,3)$ & $18,9-26,4(23,6)$ & $16,9-22,2(19,6)$ & $19,6-25,3(22,9)$ & $14,6-16,8(15,9)$ & $20,1-25,8(22,3)$ \\
\hline $\begin{array}{l}\text { 17. Comprimento do } \\
\text { acúleo dorsal }\end{array}$ & $19-25,4(22,2)$ & $25,3-35,5(30,9)$ & $19,8-26,5(23,4)$ & $22,6-33,1(27,4)$ & $16,2-18,4(17,3)$ & $22,4-28,6(25,4)$ \\
\hline $\begin{array}{l}\text { 18. Comprimento da } \\
\text { base da anal }\end{array}$ & $8,9-12,6(10,7)$ & $7,4-12,8(10,9)$ & $8,9-15,3(10,6)$ & $9,3-12,7(10,7)$ & $9,5-12,3(11,0)$ & $9-12,9(10,7)$ \\
\hline $\begin{array}{l}\text { 19. Comprimento base } \\
\text { da adiposa }\end{array}$ & $21,4-26,1 \quad(24,0)$ & $17,3-21,6(19,7)$ & $19,1-25,3(22,2)$ & $17,3-20,3(19,0)$ & $17,8-20,5(19,4)$ & $16-21,8(18,5)$ \\
\hline $\begin{array}{l}\text { 20. Comprimento da } \\
\text { nadadeira ventral }\end{array}$ & $17,1-19,7(18,3)$ & $18,4-22,2(20,5)$ & $12,4-20,2(17,5)$ & $16,9-21,9(19,9)$ & $15,6-17,4(16,6)$ & $15,8-21,5(18,9)$ \\
\hline 21. Distância dorsal adiposa & $10-15(12,5)$ & $11,5-17,9(14,2)$ & $10,8-16(12,6)$ & $11,7-17,8(14,2)$ & $12,5-20,2(15,6)$ & $11,6-17(14,4)$ \\
\hline
\end{tabular}


caudal) e do barbilhão mentoniano externo, que atinge a vertical que passa pela base do quarto raio dividido da nadadeira dorsal, mas não a base da nadadeira ventral.

Descrição. Os caracteres morfométricos estão apresentados na Tabela I. Corpo alto, com o perfil dorsal anterior inclinado, levemente convexo da ponta do focinho até a base do processo supra-occipital, levemente côncavo da vertical que passa pela margem posterior dos olhos até o meio do processo supra-occipital e levemente convexo desse ponto até a origem da nadadeira dorsal; base da nadadeira dorsal levemente côncava; reto até a origem da nadadeira adiposa e levemente inclinado ao longo da base desta. Perfil dorsal e ventral do pedúnculo caudal levemente côncavo. Perfil ventral do corpo reto na cabeça, levemente convexo do final da cabeça até a nadadeira ventral, reto do final desta até o início da nadadeira anal e levemente inclinado até o início do pedúnculo caudal.

Cabeça alta coberta por pele fina tornando conspícuas as estrias da superfície dos ossos. Focinho longo, com a narina anterior próxima ao lábio superior e a narina posterior mais próxima da narina anterior do que do olho. Fontanela anterior triangular e larga, se originando entre as narinas posteriores e não atingindo a margem orbital posterior. Processo supra-occipital triangular, forte e com numerosas estrias e vermiculações. Este atinge a placa nucal do supraneural e possui a ponta simples. Forame grande e único entre o proótico e pterosfenóide para os ramos maxilar e mandibular do nervo trigeminofacial. Olhos elípticos, de margem livre e com o comprimento longitudinal maior que a distância entre a narina posterior e a margem orbital anterior. Boca subterminal, com os lábios superior e inferior finos. Dentes pequenos, viliformes, dispostos em placas dentígeras pré-maxilares pequenas e com a margem lateral arredondada, em placas maxilares alongadas e com as margens laterais afiladas. Barbilhão maxilar alongado, ultrapassando a nadadeira adiposa, mas geralmente não atingindo a nadadeira caudal; barbilhão mentoniano externo longo, atingindo a vertical que passa pelo quarto raio dividido da nadadeira dorsal, mas não a base da nadadeira pélvica.

Rastros branquiais finos e longos, 22-27 (moda=24) rastros no primeiro arco branquial: 4-7 no ramo superior (moda=6), 1 no ângulo e 17-20 (moda=18) no ramo inferior. Membranas branquiostegais unidas anteriormente ao istmo.

Nadadeira dorsal II+6 raios, margem distal reta. Nadadeira dorsal, quando adpressa, não atinge a origem da nadadeira adiposa. Primeiro espinho dorsal muito pequeno e triangular (vista frontal), segundo espinho longo, com várias estrias longitudinais bem desenvolvidas nas superfícies laterais; margem anterior áspera e posterior denteada na metade superior. Nadadeira peitoral com I+9-10 raios. Espinho peitoral muito forte, com estrias sobre a superfície dorsal e ventral; margem anterior muito áspera, serrilhada nos dois terços proximais e margem posterior completa e fortemente serrilhada. Nadadeira pélvica com i +5 raios, originando-se na vertical que passa pela base do penúltimo raio dividido da nadadeira dorsal; quando adpressa, estende-se por 3/4 da distância que a separa da origem da nadadeira anal.
Nadadeira anal com iii-v+7-10 raios, originando-se na vertical que passa pelo primeiro terço da nadadeira adiposa. Margem posterior da nadadeira anal levemente côncava, sendo os raios anteriores mais longos do que os posteriores. Nadadeira adiposa curta, alta e triangular, se originando na linha vertical que passa pela margem posterior da nadadeira pélvica quando adpressa, antes da linha vertical que passa pelo início da nadadeira anal. Nadadeira caudal bifurcada, lobo superior ligeiramente mais longo e estreito que o inferior; raios caudais principais $i+7$ no lobo superior e $8+i$ no lobo inferior.

Coloração em álcool. Corpo com três a cinco séries de máculas grandes e escuras ao longo dos flancos; fundo variando do castanho claro ao cinza, sendo mais escuro no dorso e na cabeça; área superior dos flancos castanho claro, inferior e ventre mais claros e com tonalidade amarelada. Nadadeiras castanhas, sendo a dorsal levemente hialina e possuindo cromatóforos agrupados entre os raios, na porção 2/3 distal; sem pintas nas demais, com exceção da nadadeira adiposa e caudal que as possuem em tamanho menor que as do corpo e irregularmente distribuídas. Barbilhões maxilares e mentonianos externos acinzentados na superfície dorsal.

Distribuição. Alto rio Paraguai, na região do Pantanal.

Etimologia. O epíteto específico pantaneiro é um adjetivo pátrio, que se refere à área de distribuição da espécie, denominada Pantanal no Brasil.

Análise morfométrica multivariada. Com a análise das variáveis canônicas livres do tamanho foi possível confirmar a diferença entre as espécies de Pimelodus do rio Paraguai. Na primeira análise, foram discriminadas $P$. absconditus, $P$. maculatus (da bacia do alto rio Paraná) e P. ornatus, das demais espécies, no eixo canônico 1 (Fig. 3). A primeira variável canônica representou 59,6\% da variância da matriz original e a segunda $23,7 \%$. Nesta análise foi incluída a espécie $P$. maculatus, da bacia do alto rio Paraná, com o propósito de verificar sua discriminação das espécies do rio Paraguai e principalmente de $P$. pantaneiro. Para a separação de $P$. maculatus, as variáveis mais importantes foram os maiores valores de comprimento padrão, comprimento da base da nadadeira adiposa, distância pré-ventral e distância entre as nadadeiras ventral e anal. As variáveis mais importantes na discriminação da espécie $P$. absconditus das demais espécies foram os maiores valores de comprimento da base da nadadeira adiposa, distância entre as bases das nadadeiras ventral e anal, altura do pedúnculo caudal e comprimento da base da nadadeira dorsal. A espécie $P$. ornatus se diferenciou das demais por apresentar maiores valores de largura da boca, comprimento da cabeça, largura da cintura peitoral e comprimento do focinho (Tab. II). Nesta análise, a presença das espécies $P$. absconditus, $P$. maculatus e $P$. ornatus (muito distintas morfometricamente) provocou o agrupamento daquelas espécies mais semelhantes. Por isso foi feita uma segunda análise, para comparar somente as três espécies mais similares morfometricamente.

Na segunda análise, a espécie $P$. pantaneiro foi discriminada das espécies $P$. mysteriosus e $P$. argenteus no eixo canônico 1 , enquanto $P$. mysteriosus se discriminou de $P$. argenteus no eixo canônico 2 (Fig. 4). A 
primeira variável canônica representou $82,3 \%$ da variância da matriz original e a segunda $17,7 \%$. As variáveis mais importantes para a diferenciação da espécie $P$. pantaneiro foram a largura da boca, largura da cintura peitoral, distância interorbital e altura da cabeça, cujos valores foram maiores que nas demais espécies. Em P. mysteriosus, as variáveis com maiores valores foram a distância entre

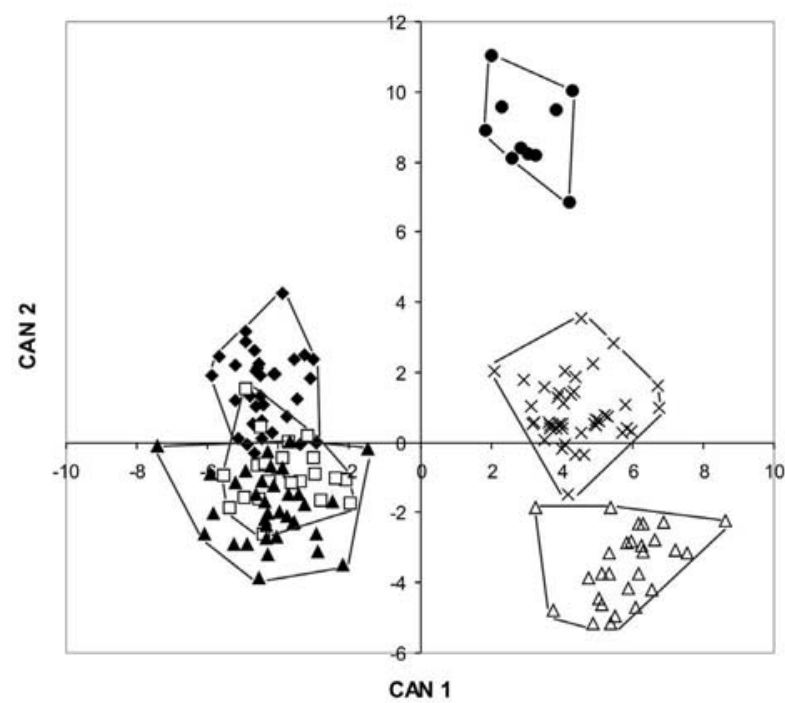

Fig. 3. Projeção dos escores individuais obtidos através da análise das variáveis canônicas livres do tamanho, com as medidas tradicionais das amostras combinadas de Pimelodus absconditus $(\triangle)$, P. argenteus $(\Delta)$, P. mysteriosus $(\square)$, P. ornatus $(\bullet), P$. pantaneiro sp. nov. $(\diamond)$ e $P$. maculatus $(\mathrm{X})$. as bases das nadadeiras ventral e anal, comprimento do barbilhão maxilar, distância pré-dorsal e largura da cintura peitoral. A espécie $P$. argenteus se discriminou das demais por apresentar maiores valores de comprimento do acúleo dorsal, diâmetro do olho, comprimento da base da nadadeira dorsal e comprimento da nadadeira ventral (Tab. III).

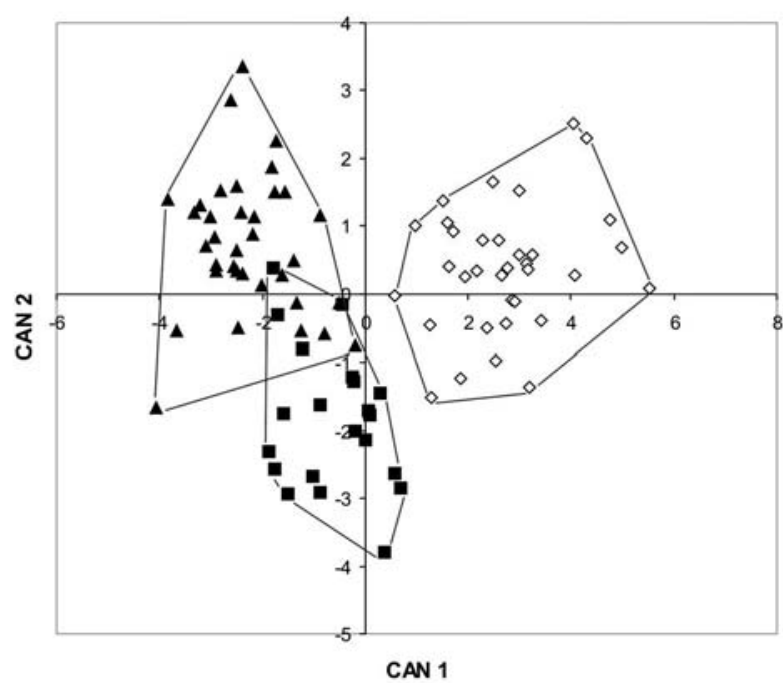

Fig. 4. Projeção dos escores individuais obtidos através da análise das variáveis canônicas livres do tamanho, com as medidas tradicionais, das amostras combinadas de Pimelodus argenteus $(\mathbf{A})$, P. mysteriosus $(\boldsymbol{\square})$, P. pantaneiro sp. nov. $(\diamond)$.

Tabela II. Coeficientes de correlação de Pearson, entre os autovetores e as variáveis tradicionais, da análise das variáveis canônicas livres do tamanho das amostras combinadas das cinco espécies de Pimelodus da bacia do alto rio Paraguai e da espécie Pimelodus maculatus da bacia do alto rio Paraná.

\begin{tabular}{|c|c|c|c|c|}
\hline Variáveis & Variável canônica 1 & Prob. & Variável canônica 2 & Prob. \\
\hline 1. Comprimento padrão & 0,89744 & 0,0001 & 0,04585 & 0,5527 \\
\hline 2. Comprimento da cabeça & 0,52324 & 0,0001 & 0,68256 & 0,0001 \\
\hline 3. Diâmetro do olho & 0,20740 & 0,0067 & $-0,33647$ & 0,0001 \\
\hline 4. Distância Interorbital & $-0,81184$ & 0,0001 & 0,45703 & 0,0001 \\
\hline 5. Comprimento do focinho & 0,57779 & 0,0001 & 0,55178 & 0,0001 \\
\hline 6. Largura da boca & $-0,16374$ & 0,0329 & 0,91752 & 0,0001 \\
\hline 7. Distância pré-dorsal & 0,43408 & 0,1492 & 0,49643 & 0,0001 \\
\hline 8. Comprimento da base da dorsal & 0,40099 & 0,0001 & $-0,24354$ & 0,0014 \\
\hline 9. Distância pré-ventral & 0,69496 & 0,0001 & 0,10205 & 0,1855 \\
\hline 10. Distância ventral anal & 0,66841 & 0,0001 & $-0,16776$ & 0,0288 \\
\hline 11. Altura da cabeça & $-0,05327$ & 0,4902 & $-0,17070$ & 0,0260 \\
\hline 12. Altura do corpo & 0,08409 & 0,2756 & $-0,33412$ & 0,0001 \\
\hline 13. Altura do pedúnculo caudal & 0,55896 & 0,0001 & $-0,32326$ & 0,0001 \\
\hline 14. Largura da cintura escapular & $-0,26531$ & 0,0005 & 0,61759 & 0,0001 \\
\hline 15. Comprimento do barbilhão maxilar & $-0,50537$ & 0,0001 & $-0,43858$ & 0,0001 \\
\hline 16. Comprimento do acúleo peitoral & $-0,51022$ & 0,0001 & $-0,46091$ & 0,0001 \\
\hline 17. Comprimento do acúleo dorsal & $-0,46960$ & 0,0001 & $-0,67578$ & 0,0001 \\
\hline 18. Comprimento da base da anal & 0,23903 & 0,0017 & 0,14242 & 0,0639 \\
\hline 19. Comprimento base da adiposa & 0,88673 & 0,0001 & $-0,25224$ & 0,0009 \\
\hline 20. Comprimento da nadadeira ventral & $-0,29551$ & 0,0001 & $-0,46994$ & 0,0001 \\
\hline 21. Distância dorsal adiposa & $-0,06702$ & 0,3852 & 0,26031 & 0,0006 \\
\hline
\end{tabular}


Tabela III. Coeficientes de correlação de Pearson, entre os autovetores e as variáveis tradicionais da análise das variáveis canônicas livres do tamanho, das amostras combinadas das espécies Pimelodus argenteus, P. mysteriosus e P. pantaneiro sp. nov., da bacia do alto rio Paraguai.

\begin{tabular}{|c|c|c|c|c|}
\hline Variáveis & Variável canônica 1 & Prob. & Variável canônica 2 & Prob. \\
\hline 1. Comprimento padrão & 0,34264 & 0,0009 & $-0,05089$ & 0,6338 \\
\hline 2. Comprimento da cabeça & 0,25026 & 0,0174 & $-0,16844$ & 0,1125 \\
\hline 3. Diâmetro do olho & $-0,59049$ & 0,0001 & $-0,07220$ & 0,4989 \\
\hline 4. Distância Interorbital & 0,62627 & 0,0001 & 0,04835 & 0,6509 \\
\hline 5. Comprimento do focinho & 0,25387 & 0,0158 & 0,02018 & 0,8502 \\
\hline 6. Largura da boca & 0,75435 & 0,0001 & 0,25364 & 0,0159 \\
\hline 7. Distância pré-dorsal & 0,20552 & 0,0520 & $-0,30353$ & 0,0036 \\
\hline 8. Comprimento da base da dorsal & $-0,52963$ & 0,0001 & 0,11775 & 0,2690 \\
\hline 9. Distância pré-ventral & 0,35992 & 0,0005 & $-0,15157$ & 0,1538 \\
\hline 10. Distância ventral anal & $-0,03783$ & 0,7234 & $-0,45472$ & 0,0001 \\
\hline 11. Altura da cabeça & 0,43131 & 0,0001 & 0,00938 & 0,9301 \\
\hline 12. Altura do corpo & 0,23340 & 0,0268 & $-0,14634$ & 0,1687 \\
\hline 13. Altura do pedúnculo caudal & 0,32957 & 0,0015 & 0,04909 & 0,6459 \\
\hline 14. Largura da cintura escapular & 0,68483 & 0,0001 & $-0,22260$ & 0,0350 \\
\hline 15. Comprimento do barbilhão maxilar & $-0,40635$ & 0,0001 & $-0,32442$ & 0,0018 \\
\hline 16. Comprimento do acúleo peitoral & $-0,37877$ & 0,0002 & 0,12997 & 0,2221 \\
\hline 17. Comprimento do acúleo dorsal & $-0,83505$ & 0,0001 & 0,04476 & 0,6753 \\
\hline 18. Comprimento da base da anal & 0,10639 & 0,3182 & 0,38987 & 0,0001 \\
\hline 19. Comprimento base da adiposa & $-0,33315$ & 0,0013 & 0,36118 & 0,0005 \\
\hline 20. Comprimento da nadadeira ventral & $-0,48102$ & 0,0001 & 0,33995 & 0,0010 \\
\hline 21. Distância dorsal adiposa & 0,07537 & 0,4802 & $-0,16221$ & 0,1266 \\
\hline
\end{tabular}

Chave para a identificação das espécies de Pimelodus da bacia do alto rio Paraguai

1. Duas faixas escuras longitudinais, uma ao longo do dorso e outra ao longo da linha lateral; uma grande mancha escura triangular na parte ântero-superior do tronco; uma grande mácula escura no meio da nadadeira dorsal; lobos da nadadeira caudal com uma faixa escura longitudinal; 13-14 rastros no primeiro arco branquial ........ P. ornatus (Fig. 5A)

1'. Corpo sem faixas longitudinais, com ou sem máculas ou pintas; 15 ou mais rastros no primeiro arco branquial

2. Corpo com máculas de diferentes tamanhos, sempre pequenas, justapostas, irregularmente distribuídas e mais conspícuas nos dois terços anteriores do corpo; 19 a 23 rastros branquiais (moda=20); diâmetro do olho maior que a distância interorbital P. absconditus (Fig. 5B)

2'. Padrão de colorido uniforme ou com máculas relativamente grandes e regularmente distribuídas em fileiras; 22 a 29 rastros no primeiro arco branquial, (moda $=24$ - 25); diâmetro do olho menor que a distância interorbital

3. Corpo sem pintas, com colorido variando do castanho escuro ao cinza prateado; acúleo dorsal muito desenvolvido, atingindo a nadadeira adiposa quando adpresso .............. P. argenteus (Fig. 5C)

3'. Máculas regularmente distribuídas pelo corpo em fileiras; acúleo dorsal não atingindo a nadadeira adiposa quando adpresso

4. Grandes máculas dispostas em três a cinco fileiras ao longo do corpo; barbilhão maxilar atinge a base da nadadeira caudal; barbilhão mentoniano externo não atinge a base da nadadeira ventral

$P$. pantaneiro $\mathrm{sp}$. nov.

4'. Três a seis séries de máculas ao longo do corpo; barbilhão maxilar bastante longo, que atinge a metade da nadadeira caudal ou a ultrapassa; barbilhão mentoniano externo atinge a base da nadadeira ventral ........... P. mysteriosus (Fig. 5D)

\section{DISCUSSÃO}

Com o presente estudo fica clara a necessidade de revisões taxonômicas de algumas espécies de peixes da região do alto rio Paraguai. Foram identificadas cinco espécies, sendo duas coincidentes com aquelas apontadas por BRITSKi et al. (1999) para o Pantanal ( $P$. argenteus e $P$. ornatus) e ainda $P$. absconditus (denominada como Pimelodus cf. fur por BRITSKI et al., 1999), P. mysteriosus e P. pantaneiro sp. nov. (anteriormente denominada como $P$. maculatus por aqueles autores).

Morfometricamente, $P$. pantaneiro se assemelha muito a $P$. argenteus, conforme pode ser observado na análise das variáveis canônicas, diferindo, entretanto, pelo padrão de coloração com pintas ou manchas. $P$. pantaneiro também se assemelha a $P$. mysteriosus quanto aos caracteres morfométricos e o padrão de colorido, sendo possível diferenciá-las principalmente pelo comprimento do barbilhão maxilar e mentoniano externo, mais longos em P. mysteriosus. Em comparação com a descrição original, os exemplares de P. mysteriosus examinados neste estudo não apresentaram um comprimento dos barbilhões maxilares e mentonianos externos tão longos (nem sempre atingiam a extremidade 


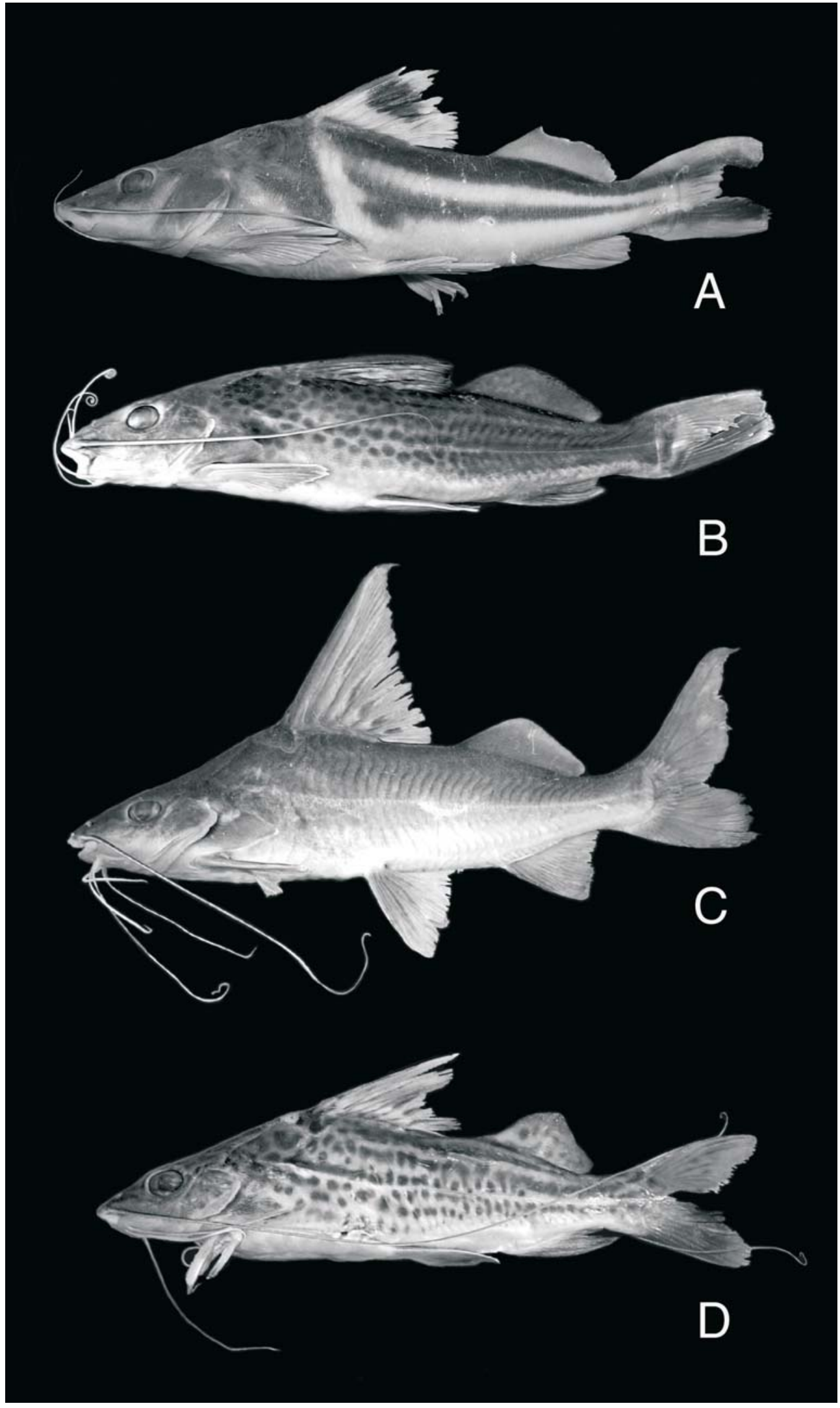

Fig. 5. A, Pimelodus ornatus, NUP 1045, 187,7 mm CP, reservatório Manso, afluente do rio Paraguai, Chapada dos Guimarães, Mato Grosso do Sul; B, Pimelodus absconditus, NUP 2228, 162,5 mm CP, reservatório Manso, afluente do rio Paraguai, Chapada dos Guimarães, Mato Grosso; C, Pimelodus argenteus, MZUL 3403, 201,5 mm CP, rio Paraguai, Porto da Manga, Pesqueiro do Rubens, Corumbá, Mato Grosso do Sul; D, Pimelodus mysteriosus, NUP 1006, 111,2 mm CP, reservatório Manso, afluente do rio Paraguai, Chapada dos Guimarães, Mato Grosso. 
dos lóbulos caudais), além de maior variação da coloração, com três a seis fileiras de pintas nos flancos contra três a quatro da descrição original. Isso pode ser explicado porque os espécimes utilizados na descrição original foram geralmente menores e com pouca variação de tamanho (83,6-143,2 $\mathrm{mm}$ de CP), em relação aos utilizados neste estudo (57,7-205,4 $\mathrm{mm}$ de $\mathrm{CP}$, cujos exemplares menores apresentavam barbilhões maxilares e mentonianos relativamente maiores). Mesmo assim, esta espécie foi identificada como P. mysteriosus, pois a maioria dos exemplares apresentou características segundo a descrição feita por AzPELICUETA (1998).

Conforme pode ser verificado na descrição e na figura apresentadas no trabalho de BRITSKI et al. (1999), $P$. pantaneiro, foi identificado como $P$. maculatus $\mathrm{La}$ Cepède, 1803 por aqueles autores. Esta espécie nova pode ser confundida com $P$. maculatus principalmente quanto à coloração, uma vez que ambas apresentam de três a cinco séries de grandes máculas nos flancos. Entretanto, $P$. pantaneiro difere de $P$. maculatus pelas características apresentadas na sua diagnose. Além disso, como apontado no parágrafo anterior, $P$. pantaneiro apresentou maior semelhança morfométrica com $P$. mysteriosus e com $P$. argenteus do que com $P$. maculatus.

Analisando os caracteres osteológicos de $P$. pantaneiro e confrontando com as informações apresentadas por AzPELICUETA (1998), verificaram-se diferenças entre essa espécie e $P$. maculatus no que concerne ao maior número e disposição das serras do acúleo peitoral, à forma do conjunto dos ossos supraneural, primeiro e segundo pterigióforos dorsais e à disposição dos ossos do suspensório (onde ocorre contato entre a região posterior ventral do metapterigóide com o osso quadrado). Além disso, esta espécie difere de $P$. mysteriosus pelo urohial afilado na região posterior, e a extremidade do processo supra-occipital ligeiramente bífido.

A análise de lotes de $P$. maculatus do alto rio Paraná, do rio Uruguai e do rio La Plata neste estudo comprovam que se tratam da mesma espécie. Análises de DNA através da técnica RAPD, indicam que a espécie $P$. maculatus do alto rio Paraná é geneticamente similar à da região do rio da Prata (Fernanda S. de Almeida, com. pess.), possibilitando afirmar que se tratam da mesma espécie. Entretanto, em estudo citogenético de populações de $P$. maculatus do alto rio Paraná e do alto rio Paraguai $(=P$. pantaneiro) foram encontradas diferenças cariotípicas que reforçam a hipótese de duas espécies distintas (SouzA et al., 2003). No estudo com DNA (Fernanda S. de Almeida, com. pess.), a diferenciação molecular entre $P$. maculatus do alto rio Paraná e do alto rio Paraguai $(=P$. pantaneiro $)$ também foi confirmada.

A ausência de $P$. maculatus na bacia do alto rio Paraguai não era esperada, uma vez que a espécie foi descrita para a bacia do rio da Prata e não existem barreiras naturais ou antrópicas que dificultem a sua dispersão. Portanto, é difícil supor que fatores vicariantes tenham isolado essas espécies, até mesmo porque $P$. absconditus e $P$. mysteriosus podem ser encontrados tanto no alto rio
Paraguai quanto no médio-baixo rio Paraná (e não foi verificado se $P$. pantaneiro está ausente nesta última região). Assim, somente um exame mais amplo de exemplares das bacias dos rios Paraguai e Paraná, com a inclusão de mais pontos de coletas, poderá auxiliar na elucidação da alopatria das duas espécies.

Agradecimentos. Ao Francisco Langeani Neto, Ricardo Cardoso Benine e revisores anônimos da revista pela leitura crítica do texto e sugestões; a Evoy Zaniboni Filho pela doação de material, a Carla Simone Pavanelli e Julio Cesar Garavello pelo empréstimo de material; ao Mauro Caetano Filho, Julio Hermann Leonhardt, Lenice Souza Shibatta e Edson Santana da Silva pela coleta de exemplares; ao Programa de Pós-Graduação em Ciências Biológicas da Universidade Estadual de Londrina pelo apoio ao trabalho; ao Osvaldo Oyakawa por realizar o depósito do material tipo no MZUSP. Os autores participam como colaboradores do projeto "All Catfishes Species Inventory" (NSF DEB-0315963).

\section{REFERÊNCIAS BIBLIOGRÁFICAS}

Azpelicueta, M. M. 1995. Pimelodus absconditus, a new species of Pimelodid catfish from de la Plata Basin (Siluriformes: Pimelodidae). Ichthyological Exploration of Freshwaters 1(6):71-76.

Azpelicueta, M. M. 1998. A new species of Pimelodus (Siluriformes, Pimelodidae) from the Paraguay and lower Paraná rivers. Geotrópica 44:87-94.

Britski, H. A. 1972. Peixes de água doce do estado de São Paulo: Sistemática. In: Comissão Interestadual da Bacia Paraná-Uruguai eds. Poluição e Piscicultura. São Paulo, Faculdade de Saúde Pública da USP e Instituto de Pesca. p.79-107.

Britski, H. A.; De Silimon, K. Z. De S. \& Lopes, B. S. 1999. Peixes do Pantanal: Manual de identificação. Brasília, Embrapa. 184p.

Eigenmann, C. H. \& Eigenmann, R. S. 1890. A revision of South American nematognathi or cat-fishes. San Francisco, California Academy of Sciences p.162-183.

Lundberg, J. G.; Mago-Leccia, F. \& Nass, P. 1991. Exallodontus aguanai, a new genus and species of Pimelodidae (Pisces: Siluriformes) from deep river channels of South America, and delimitation of the subfamily Pimelodinae. Proceedings of the Biological Society of Washington 104(4):840-869.

Lundberg, J. G. \& Littmann, M. W. 2003. Family Pimelodidae (Long-whiskered catfishes). In: Reis, E. R.; Kullander, S. O. \& FerRARIS-Jr., C. J. eds. Check List of the Freshwater Fishes of South and Central America. Porto Alegre, Edipucrs. p. $432-446$.

Lundberg, J. G. \& Parisi, B. M. 2002. Propimelodus, new genus, and redescription of Pimelodus eigenmanni Van der Stigchel 1946, a long-recognized yet poorly-known South American catfish (Pimelodidae: Siluriformes). Proceedings of the Academy of Natural Sciences of Philadelphia 152:75-88.

Mees, G. F. 1974. Auchenipteridae and Pimelodidae of Suriname (Pisces, Nematognathi). Zoologische Verhandelingen 132: $130-142$.

Reis, S. F.; Pessôa, L. M. \& Strauss, R. E. 1990. Application of size-free canonical discriminant analysis to studies of geographic differentiation. Revista Brasileira de Genética 13(3):509-520

Ringuelet, R. A.; Arámburu, R. H. \& Arámburu, A. A. 1967. Los Peces Argentinos de Agua Dulce. La Plata, Comisión de Investigaciones Científicas de la provincia de Buenos Aires. $602 \mathrm{p}$.

Souza, L.; Caetano, L. G. \& Dias, A. L. 2003. Karyotypic study of three species of Pimelodus (Pisces, Pimelodidae) from the Paraguai River Basin. Cytologia 68(4):345-350.

Willink, P. W.; Chernoff, B.; Alonso, L. E.; Montambault, J. R. \& Lourival, R. 2000. A biological assessment of the Aquatic Ecosystems of the Pantanal, Mato Grosso do Sul, Brasil. RAP Bulletin of Biological Assessment 18. Washington, Conservation International. 306p.

Recebido em agosto de 2005. Aceito em junho de 2007. ISSN 0073-4721

Artigo disponível em: www.scielo.br/isz 